\title{
Why Do Consumers Share Content on the Internet? The Uses and Gratifications Approach: An Abstract
}

\author{
Cheng-Chieh Hsiao
}

\begin{abstract}
With the advance of Web 2.0 technologies, user-generated content has become more and more prevalent on the Internet. Consumers can publish their own articles, share photos or videos, express their opinions, and interact with other consumers on the Web (Stefanone \& Lackaff, 2009). The Internet has become an important communication technology that allows consumers to share content that is generated by themselves. Drawing upon uses and gratifications theory (Rubin, 1984; Rubin \& Perse, 1987), this study attempts to examine how consumers' motives for Internet use influence their online content sharing behavior. Life satisfaction and Internet satisfaction are also included as different representations of gratifications received when consumers use the Internet. After analyzing 873 responses collected from a national representative sample, the results show that ritualized motive is related to Internet satisfaction positively, and social motive affects life satisfaction and Internet satisfaction positively. Both life satisfaction and Internet satisfaction have positive impacts on consumer content sharing behavior on the Internet. Finally, this study concludes with several theoretical and practical implications.
\end{abstract}

References Available Upon Request

C.-C. Hsiao $(\bowtie)$

Shih Hsin University, Taipei, Taiwan, China

e-mail: jerrycchsiao@gmail.com 